\title{
The growth of the IFHGS after 2000
}

\author{
Jean-Jacques Cassiman \\ European Journal of Human Genetics (2017) 25, S45-S46; doi:10.1038/ejhg.2017.154
}

The creation of the IFHGS in 1996 by the three, at that time fairly well-organised, continental societies and the end of the claim of the remaining members of the Permanent Committee of the International Congress, allowed the executive committee of the IFSHG to focus on its major aim to create a global platform of human geneticists. Other national societies and regional societies or loosely composed groups of geneticists were motivated to create the structure necessary to become a democratic and organised regional society that could join the Federation. Different members of the founding societies (Marcus Pembrey, Judith Allanson, Ségolène Aymé, Eric Haan, Elaine Strass, and myself, to mention just a few) attended congresses and symposia in different places all over the world, and used this opportunity to explain the need and purpose for the existence of the IFHGS. Possible strategies were reviewed with the local representatives of these bodies on how to create an organisation, which could fulfill the requirements needed to become full members. In many cases, personal contact with local leaders by members of the executive committee or their colleagues helped to gradually pave the way to this goal. It was clear, however, that the history of the local organisation or of individuals in those organisations was not always conducive to facilitating an agreement between parties, which at first sight seemed to be better suited to the creation of a regional or continental structure.

Over the years, the East Asian Union of Human Genetic Societies, the Latin American Network of Human Genetic Societies, and the Asia Pacific Society of Human Genetics were able to fulfill the criteria for full membership. The last to join was the African Society of Human Genetics. Most regions of the world are now represented in the IFHGS, which enables it to be aware of genetic issues worldwide and to be in contact with the genetics community in almost all regions of the world.

Presidents or past presidents of the different full member societies succeeded each other as presidents of the IFHGS, with terms of 3 years. In the first 21 years of the Federation, six presidents have taken office: Ségolène Aymé (ESHG), Uta Francke (ASHG), Eric Haan (HGSA), Jose-Maria Cantu (LANHGS), Yoichi Matsubara (EAUHGS), Stephen Lam (APSHG), and Helena Kääriäinen (ESHG). After the International Congress in Rio de Janeiro in 1996, the first - more or less - organised by the newborn IFHGS, it was made very clear that further international congresses (ICHG) would be the sole responsibility of the Federation and that the full members would take it in turn to organise these every 5 years. The congresses in Vienna (2001), Brisbane (2006), Montreal (2011), and Kyoto (2016) further established the authority of the Federation. The scientific programme of these ICHGs was the responsibility of the scientific programme committee of the organising society, but colleagues from full member organisations were always invited to participate in the preparations.
National genetic societies, professional organisations, and others could apply for different types of membership adapted to their structure or their activities. As described in the bylaws of the Federation, the IFHGS accepted corresponding membership (multidisciplinary societies), affiliate membership (a national or international organisation representing a specialty dedicated to human genetics), and preliminary membership (a newly formed organisation dedicated to human genetics in a country without a national society). At present, the Federation comprises 47 corresponding members, mainly national societies from all continents, nine affiliate members including the IGA (the International Genetic Alliance), HUGO (the Genome International Organisation Limited), the Human Variome Project International, and the International Genetic Epidemiology Society.

Over the years, the Federation discussed how to improve international dissemination of information about human genetics, how guidelines and recommendations on procedures and service provision could be improved, and how support could be given to developing societies and their meetings in different regions of the world. On a few occasions, it also organised a workshop at the ICHG, for example, the Symposium on Guidelines for Developing Countries in Brisbane. Many of these issues were also discussed with numerous international organisations such as WHO, IGA, and the Human Variome Project. Through these formal meetings, the Federation became the means by which these organisations could interact with the international genetics community.

At many executive meetings, ideas were tabled on how the Federation could improve its support for the global genetics community. Proposals to set up a 'Distinguished Speakers' panel, or something of that nature, which could allow members to find speakers on important topics for their meetings, set up committees for the development of guidelines, or suggest to members who had developed guidelines or recommendations to submit them for endorsement or approval by the Federation were discussed many times. The representatives had, however, to accept the reality that the different member societies do not necessarily all follow the same procedures when such documents are produced and approved. The possibility of using this 'platform' is still available, but it has not often been exploited.

During the initial period of its creation and during many years following it, Elaine Strass, Executive Director of the ASHG and an active supporter of the Federation, also provided kind and enthusiastic support for the secretarial and administrative needs of the Federation. After Elaine retired in 2009, it became clear that another full member of the Federation would have to take on that responsibility. Jerome del Picchia, Executive Officer of the ESHG, did not need to be asked twice, and took over the secretariat of the IFHGS in 2010. 
It is clear that in this era of global communication and exchange of information, when human and molecular genetics have become an essential expertise in medical practice and at a time when rare diseases are finally receiving the attention they deserve, the IFHGS continues to have an important role for the genetics community. Today, we should be grateful that some of our colleagues (Marcus Pembrey, Ségolène Aymé, and so on) had the foresight to start working on the creation of what today is still a very important organisation.

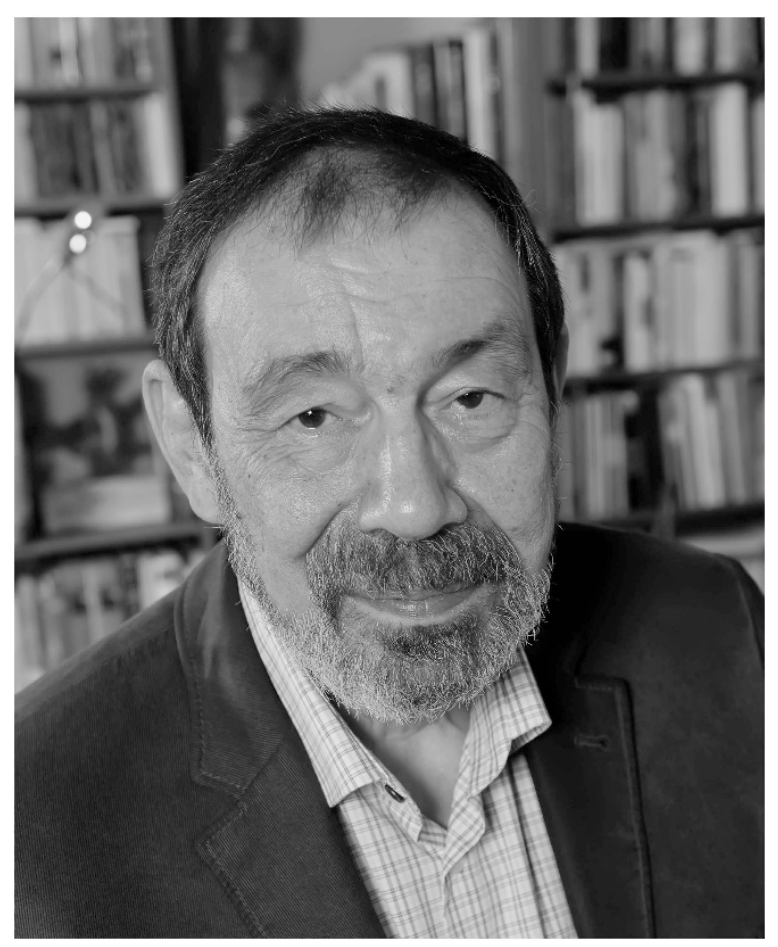

Jean-Jacques Cassiman

Jean-Jacques Cassiman, born on 25 April 1943 in Brussels, trained as MD with specialty in paediatrics, at the University of Leuven, Belgium and spent 5 years as post-doctoral fellow at the University of Stanford, CA, USA. In 1984, he was appointed full Professor of Human Genetics and in 1999, division head of the Centre for Human Genetics in Leuven. Since 2008, he is emeritus professor of the KU Leuven. He was in charge of the molecular diagnostic facilities of the Centre and Director of the laboratory for forensic genetics and molecular archeology. He coordinated a number of EU research projects on cystic fibrosis and the EU-funded Network of Excellence EUROGENTEST (2005-2010), aimed at harmonising and improving the quality of genetic testing in the EU.

He held the Francqui chair at the Catholic University of Louvain (1998). He is Doctor Honoris Causa (2002) of the University of Medicine and Pharmacy of Cluj Napoca (Romania), of the Catholic University Santiago de Guayaquil, Ecuador (2003), and of the University of Hasselt, Belgium (2013). He was secretary general of the European Society of Human Genetics (1993-1999); liaison officer for the ESHG to the International Federation of Human Genetics Societies (2002-2008), and President of the ESHG (2008-2009). He was secretary of EPPOSI (European Platform for Patient Organisations, Science, and Industry); vice president of the Institute for Science and Technological aspects, Flemish Parliament; vice president of the Belgian Cystic fibrosis Society, and is Chair of the Fund for Rare diseases and Orphan drugs of the King Baudouin Foundation, member of the board of directors of 'Biopontis Alliance for Rare Diseases' and of the European Foundation of Good Clinical Practice (EFGCP), President of the Flemish League against Cancer, and member of the Belgian Federal Commission on Embryo research.

His genes have been passed on over two generations. 